\title{
DEMONSTRASI PENGGUNAAN ALAT PENANGKAP CUMI-CUMI (Loligo sp.) SQUID JIGGING M. V. SEAFDEC-2 DI LAUT CINA SELATAN
}

\author{
Agus Salim 1 ) \\ 1) Teknisi Litkayasa pada Balai Riset Perikanan Laut, Muara Baru-Jakarta \\ Teregristasi I tanggal: 19 September 2006; Diterima setelah perbaikan tanggal: 27 Maret 2007; \\ Disetujui terbit tanggal: 25 September 2007
}

\section{PENDAHULUAN}

Laut Cina Selatan merupakan landas kontinen dengan rata-rata kedalaman mencapai $70 \mathrm{~m}$ dengan keadaan dasar perairan yang datar dan stratifikasi massa air dipengaruhi oleh musim (Wyrtki, 1961). Luas Laut Cina Selatan termasuk wilayah perairan Indonesia diduga $595.000 \mathrm{~km}^{2}$ (SCS, 1979; Cholik et al., 1995).

Sumber daya ikan pelagis kecil dari Laut Cina Selatan telah dimanfaatkan oleh para nelayan dari daerah sekitar baik di dalam wilayah Republik Indonesia (Kalimantan Barat, Riau, dan Sumatera Selatan) maupun di luar wilayah Indonesia yang berbatasan langsung seperti Malaysia, Thailand, dan Brunei.

Cumi-cumi (Loligo sp.) adalah salah satu dari sumber daya ikan pelagis yang juga dihasilkan dari perairan Laut Cina Selatan. Menurut Badrudin \& Mubarak (1998) tingkat pemanfaatan cumi-cumi (Loligo sp.) di perairan tersebut mencapai 78\%.
Tujuan dari kegiatan ini adalah untuk mengetahui cara kerja atau cara pengoperasian, hasil tangkapan, dan dimensi alat tangkap pancing cumi-cumi (Loligo sp.).

\section{DAERAH PENELITIAN}

Penelitian tentang sumber daya perikanan di Laut Cina Selatan Iahan Kalimantan bagian barat telah dilakukan pada tanggal 13 Juni sampai dengan 2 Juli 2005. Penelitian dilakukan dengan menggunakan alat tangkap traw/ di atas kapal M. V. Seafdec-2 yang dilengkapai dengan peralatan modern dan diikuti oleh 4 negara yang berbatasan langsung dengan Laut Cina Selatan yaitu Indonesia, Thailand, Malaysia, dan Brunei. Lokasi penelitian dapat dilihat pada Gambar 1.

Dalam penulisan ini dititikberatkan pada alat penangkap cumi-cumi (Loligo sp.) yang bekerja dengan bantuan mesin penarik pancing dan cahaya lampu halogen yang bertujuan untuk daya tarik pengumpul cumi-cumi (Loligo sp.).

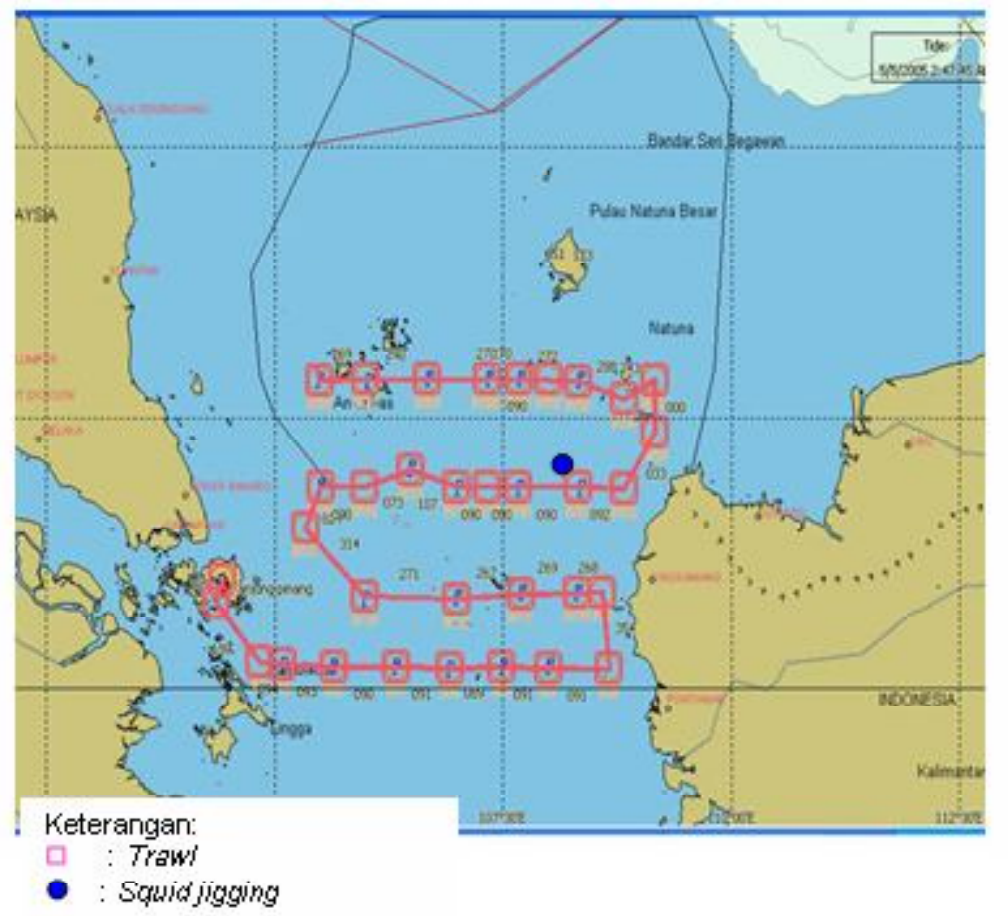

Gambar 1. Lokasi penelitian M. V. Seafdec-2. 


\section{DESKRIPSI ALAT TANGKAP}

Penangkapan cumi-cumi (Loligo sp.) secara otomatis dengan menggunakan bantuan mesin adalah cara yang dapat dilakukan dengan mudah dan membutuhkan tenaga manusia relatif lebih sedikit dibanding alat penangkap cumi-cumi (Loligosp.) yang lain. Pancing cumi-cumi (Loligo sp.) ini merupakan alat tangkap yang ramah lingkungan dan selektif terhadap hasil tangkapan. Deskripsi pancing cumicumi (Loligo sp.) dapat dilihat pada Gambar 2.
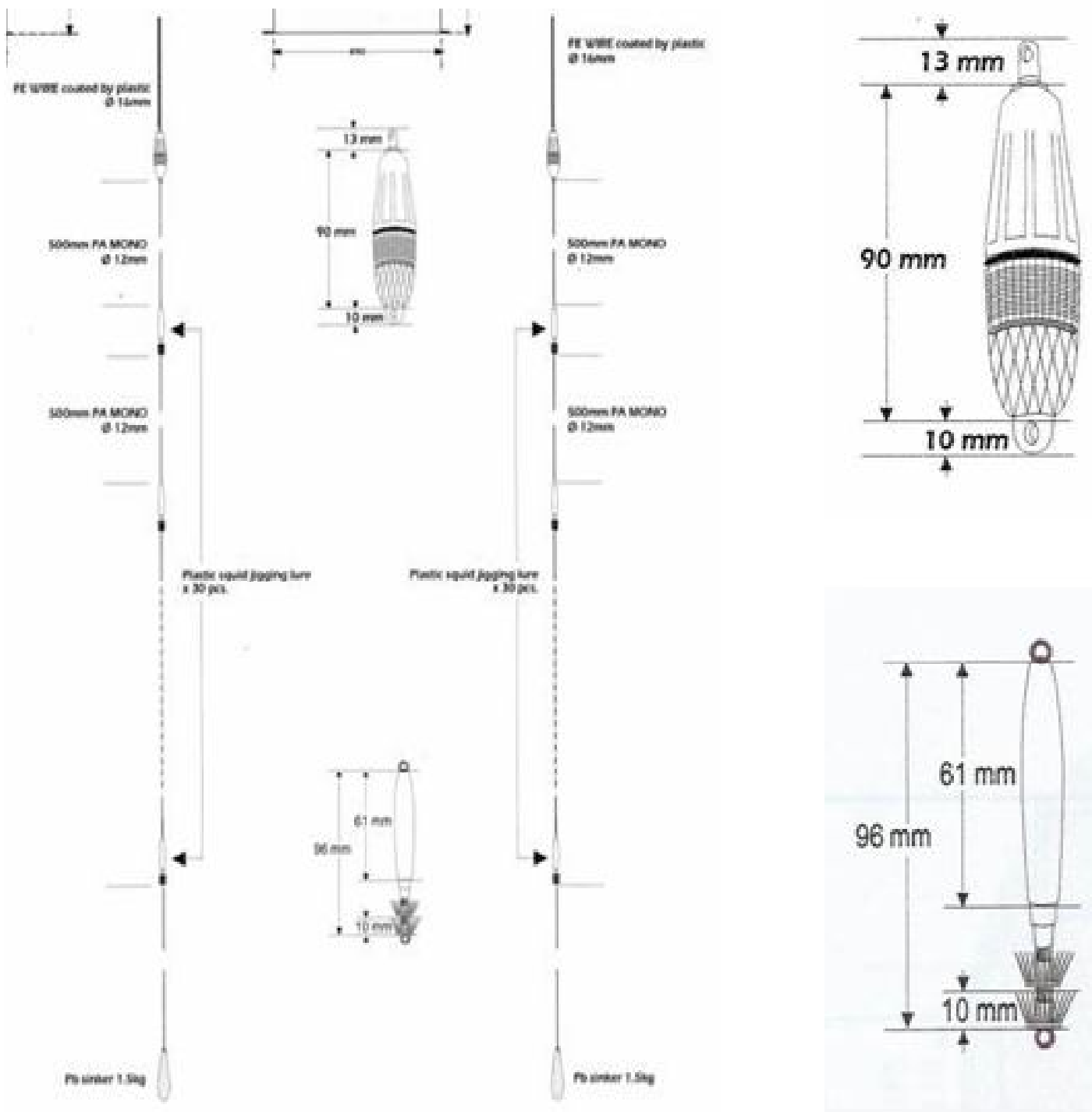

Gambar 2. Deskripsi pancing cumi-cumi (Loligo sp.).

Alat ini menggunakan mesin pancing cumi-cumi (Loligo sp.) yang bergerak secara otomatis naik turun ke dalam perairan dengan kedalaman dan waktu yang dapat ditentukan oleh operator mesin. Tali pancing terbuat dari bahan nylon mono filament (serat tunggal), setiap tali pancing terdapat 20 sampai dengan 25 mata pancing yang terbuat dari bahan plastik dengan warna mencolok yang dapat dioperasikan sampai dengan kedalaman 250 sampai dengan $300 \mathrm{~m}$ tergantung kedalaman yang diinginkan dan panjang tali pancing yang tersedia (Gambar 3). Dalam pengoperasian dilakukan dengan kapal dalam keadaan stasionerdan menggunakan bantuan lampu jenis halogen berdaya 3 KW 4 buah yang bertujuan untuk daya tarik pengumpul cumi yang dipasang tepat di atas mesin pancing (Gambar 4). 

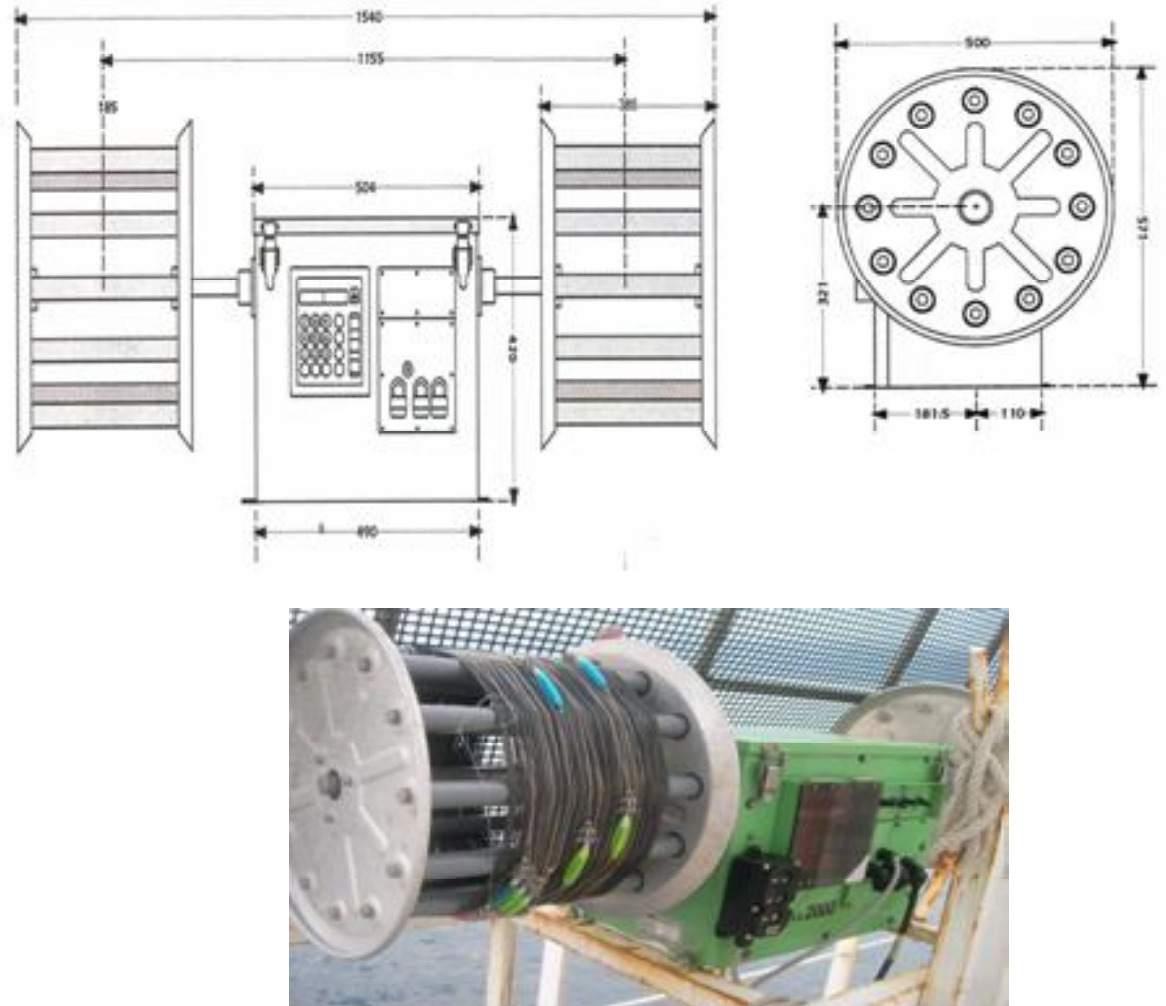

Gambar 3. Desain mesin pancing cumi-cumi (Loligo sp.).

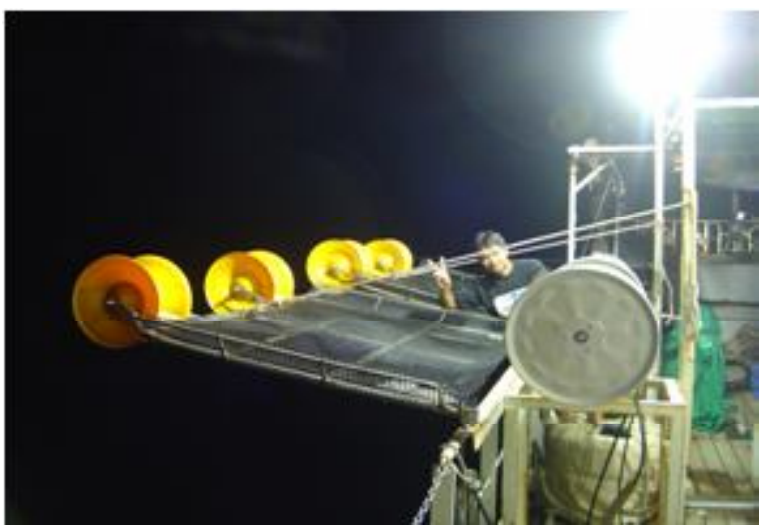

Gambar 4. Alat tangkap cumi-cumi (Loligo sp.) dengan lampu halogen $3 \mathrm{KW}$.

\section{Cara Pengoperasian}

Pengoperasian squid jigger dilakukan pada posisi $01^{\circ} 51^{\prime} 26^{\prime \prime} \mathrm{N}-108^{\circ} 20^{\prime} 05^{\prime \prime E}$. dengan kedalaman air mencapai $60 \mathrm{~m}$. Tali pancing dipasang sampai dengan kedalaman $50 \mathrm{~m}$ dengan lama operasi 5 jam.

Setelah sampai dengan stasiun yang telah ditentukan informasi mengenai keadaan cuaca dan kondisi oseanografi perairan dikumpulkan untuk memperlancar operasi penangkapan yang akan dilakukan. Sebelum operasi dimulai dibutuhkan waktu selama kurang lebih 1 jam untuk mempersiapkan peralatan yang dibutuhkan seperti penurunan jangkar (stasioner), menghidupkan lampu, pancing, dan mesin penarik pancing. Pengoperasian alat dimulai pada jam 20.00 sampai dengan 03.00 WIB. Penyinaran dengan lampu halogen dilakukan selama 1 sampai dengan 2 jam sebelum operasi dimulai.

\section{Hasil Tangkapan}

Dalam demonstrasi alat ini hasil tangkapan yang diperoleh selama 5 jam pengoperasian alat ini 2,25 $\mathrm{kg}$ dengan jumlah 25 ekor yang didominasi oleh cumicumi jenis Loligo singhalensis, Loligo edulis, dan Loligo duvaucelli (Tabel 1). Jumlah hasil tangkapan yang sedikit ini ada dugaan dipengaruhi oleh cahaya bulan dan kurang musim penangkapan cumi-cumi (Loligo sp.) yang bersifat fototaksis positif. 
Tabel $1 . \quad$ Hasil tangkapan squid jigger

\begin{tabular}{|c|c|c|c|c|c|c|c|c|}
\hline \multirow[t]{2}{*}{ Ho. } & \multirow[t]{2}{*}{ Jenis } & \multirow[t]{2}{*}{ Jumlah } & \multicolumn{2}{|c|}{$\begin{array}{c}\text { Bobot } \\
\text { (g) }\end{array}$} & \multicolumn{2}{|c|}{$\begin{array}{l}\mathbf{M L} \\
\text { (cm) }\end{array}$} & \multicolumn{2}{|c|}{$\begin{array}{l}\text { TtL } \\
\text { (cm) }\end{array}$} \\
\hline & & & Kisaran & Rataan & Kisaran & Rataan & Kisaran & Rataan \\
\hline 1. & Loligo edinis & 12 & $50-250$ & 117,92 & $9,1-40,0$ & 19,24 & $8,3-20$ & 13,975 \\
\hline 2. & Loligo singhalensis & 10 & $7-150$ & 64,70 & $8,3-24$ & 14,74 & $4,9-12$ & 9,40 \\
\hline 3. & Loligo duvaucell & 3 & $100-140$ & 120,00 & $14,1-20$ & 17,20 & $10-17$ & 13,10 \\
\hline
\end{tabular}

Keterangan: $\mathrm{ML}=$ mantel length (panjang mantel); $\mathrm{TtL}=$ tentackle length (panjang tentakel)

\section{KESIMPULAN}

1. Alat tangkap squid jigging merupakan alat yang selektif terhadap hasil tangkapan dan ramah lingkungan.

2. Dapat dioperasikan pada kedalaman yang diinginkan.

\section{DAFTAR PUSTAKA}

Badrudin, M. \& H. Mubarak. 1998.Sumber daya cumicumi (Loligo sp.). Potensi dan Penyebaran Sumber Daya Ikan Laut di Perairan Indonesia. Direktorat Jenderal Perikanan. Pusat Penelitian dan Pengembangan Oseanologi Lembaga IImu Pengetahuan Indonesia. Pusat Penelitian dan
Pengembangan Perikanan Departemen Pertanian. Lapan. BPPT dan Faperikan Institut Pertanian Bogor. 164-168.

Cholik, F., M. F. Sukadi, S. Nurhakim, I G. S. Merta, \& J. Widodo. 1995. Evaluasi pengkajian sumber daya perikanan laut. Pusat Penelitian dan Pengembangan Perikanan. Badan Penelitian dan Pengembangan Pertanian. 15 hal.

SCS. 1979. Report of workshop on demersal and pelagic fish resources in the Java Sea. SEAFDEC. SCS (Gen/79/20). $19 \mathrm{p}$.

Wyrtki, K. 1961. Physical oceanography of the southeast Asian waters. Naga. Rep. 2:195 p. 